Article

\title{
The Lubricity of Ternary Fuel Mixture Blends as a Way to Assess Diesel Engine Durability
}

\author{
Abul Kalam Azad *, Mohammad Golam Rasul, Subhash Chandra Sharma and \\ Mohammad Masud Kamal Khan \\ School of Engineering and Technology, Central Queensland University, Melbourne, VIC 3000, Australia; \\ m.rasul@cqu.edu.au (M.G.R.); s.sharma2@cqu.edu.au (S.C.S.); m.khan@cqu.edu.au (M.M.K.K.) \\ * Correspondence: azad.cqu@gmail.com or a.k.azad@cqu.edu.au; Tel.: +61-469-235-722
}

Received: 1 October 2017; Accepted: 18 December 2017; Published: 24 December 2017

\begin{abstract}
The study deals with the lubrication characteristics of ternary fuel mixture blends to assess diesel engine durability by using better performing fuels, namely Mandarin Crambe and Paraffin (ManCr_Pa) and Avocado Bush nut and Paraffin (AvBn_Pa). Tribological parameters of friction coefficient, wear, and lubrication stability were measured to assess the impact of these fuels on engine durability. The tests were conducted on a four-ball tribotester using the American Society for Testing Materials (ASTM) D4172 standard; friction coefficient and wear scar diameter for the fuels were measured. The wear scar surface morphology of the ball metals was evaluated by a high-performance scanning electron microscope with energy dispersive X-ray SEM/EDX analysis. The corrosive behaviour of the fuels was also assessed by evaluating images from the SEM/EDX tests. Finally, the engine durability, reliability, and longevity were also evaluated based on the measured tribological parameters.
\end{abstract}

Keywords: biodiesel; lubrication properties; tribological characteristics; friction coefficient; SEM/EDX analysis

\section{Introduction}

The tribological aspects of internal combustion engine systems mainly deal with the reciprocating motion of the cylinder and the piston. When the engine runs, the piston slides on the inner surface of the cylinder, and friction is produced between the mating surfaces which gives rise to wear on both of them. Thus, the energy produced by fuel combustion is partially consumed to overcome friction which reduces the engine efficiency by up to $20 \%$, as reported by Nagar and Miers [1]. Clearances are increased due to cylinder and piston wear, giving rise to blow-by of gases which also contributes to further reducing the efficiency.

Lubrication of piston and cylinder surfaces occurs mainly as a boundary lubrication regime, and a very thin film of normally less than a micron in thickness is formed in the contact zone giving a lambda ratio $\left(\lambda_{l}\right)$ between 1.0 and 1.5 [2]. This is the ratio between the film thickness and composite roughness of the two surfaces. The lubrication is used to minimise the friction and wear by creating a very thin layer between the metal surfaces. However, it involves additional cost and the constituents such as $\mathrm{Fe}, \mathrm{Cr}, \mathrm{P}, \mathrm{Zn}$, etc. added into the lubricating oil cause more particulate matter (PM) formation when they are mixed with the exhaust gases near the cylinder wall. It is also reported in the literature that adding additives in a lubricating oil causes environmental pollution due to higher contents of sulphur and phosphorus [2,3]. Therefore, lubrication is important for not only conserving energy but also for safe running of engines as reported by Tung and McMillan [4]. Mosarof et al. [5] also reported that about 33\% of total energy losses in passenger cars are due to friction of their moving parts [6]. Some other techniques such as coating, texturing and application of lighter metal that have also been used to minimise friction [2]. 
Biodiesel can be used to minimise environmental pollution and also the dependency on lubricating oil due to its excellent self-lubricating properties [7-9]. The literature also reports that vegetable oils such as soybean, sunflower, coconut, corn, moringa and rice bran oils can be used as bio-lubricants in compression ignition (CI) engines $[4,10,11]$. The lubricating property of the biodiesel depends on the dynamic viscosity of the fuel which is related to its density and the kinematic viscosity for a given operating temperature [12-14]. Other research reveals that the wear and friction decrease with the increase in biodiesel blend percentage as investigated by Fazal et al. [15]. On the other hand, Haseeb et al. [16] experimented on the variation of wear and friction of a biodiesel drive with palm oil at temperatures of $30,45,60$ and $75^{\circ} \mathrm{C}$. They found that both wear and friction increased with the increase of cylinder wall temperature.

Mosarof et al. [17] and Habibullah et al. [7] investigated the tribological characteristics of biodiesel produced from Calophyllum inophyllum under different load conditions in a CI engine. Their results revealed that wear and friction increase with an increase in applied load, but decrease with the increase of biodiesel blends at constant load. Many other researchers used a four-ball triobotester to analyse the tribological behaviour of different biodiesels as reported in the literature $[2,7,16]$. Four-ball testers are widely used by lubricant manufacturers in research and development (R\&D) of new lubricants and characterising their friction and wear behaviour.

The internal combustion (IC) engine combustion system involves both moving and stationary parts such as the piston reciprocating inside the cylinder. When the engine runs, they produce friction forces which cause wear between the contact surfaces of the sliding components. Engine life and reliability degrades due to this effect which amplifies the maintenance cost of the engine $[18,19]$. Lubrication undertakes an important role to minimise this effect. As a result, fuel (such as biodiesel) with self-lubricating characteristics can enhance engine life as well as improve engine durability and reliability [20]. It is important to analyse the friction, wear and corrosive characteristics of any new fuel to maintain engine durability before introducing it to the engine. The coefficient of friction and the wear scar diameter analysis quantifies the parametric analysis of friction and wear of the engine. In addition, cylinder metal surface morphology can be analysed by an optical microscope and scanning electron microscope (SEM) with energy dispersive X-ray spectroscopy (EDX) analysis.

Recently, Mosarof et al. [17] investigated the friction and wear characteristics of Calophyllum inophyllum biodiesel B100 and palm biodiesel blend B10 and B20 at different temperatures and load conditions with constant speed. They found higher metal elements in pure biodiesel and lower metal elements in blends [17]. They also investigated lubrication characteristics of Millettia pinnata and rice bran biodiesel [5]. They found that Millettia pinnata resulted in a low coefficient of friction which indicates better lubricating performance and rice bran biodiesel demonstrated lower wear scar diameter. Fazal et al. [21] investigated the corrosive behaviour of biodiesel for long term durability of the engine moving parts. They experimented and compared corrosive characteristics of the tested biodiesel on aluminium, copper and stainless steel metal at $80^{\circ} \mathrm{C}$ temperature for a period of $1200 \mathrm{~h}$. They found that biodiesel does not attack stainless steel, but copper and aluminium were more susceptible to attack by the fuel in comparison to diesel. It is obvious that a tribological study of any new fuel is important to ensure sustainable engine durability.

This study performed tribological testing using a four-ball tribotester in accordance with the ASTM D4172 standard whereby friction coefficient (FC) and wear scar diameter (WSD) were measured for the tested fuels. The wear scar surface morphology of the ball metals was further evaluated by a high-performance scanning electron microscope (SEM) with energy dispersive X-ray (EDX) analysis.

\section{Materials and Methods}

In this study, the key fuel properties such as density, kinematic viscosity, calorific value, flash point, acid value, oxidation stability, ester content, cetane number, and iodine number were measured in accordance with the ASTM and European (EN) standards. The lubrication properties of two ternary fuels mixture blends prepared by mixing two biodiesels with paraffin into diesel. The first blend was 
prepared by mixing 3\% Mandarin biodiesel and 2\% Crambe biodiesel with $4 \%$ paraffin by volume and rest of the $91 \%$ is diesel which is presented as ManCr_Pa. Similarly, a second blend was prepared by mixing 3\% avocado and $2 \%$ bush nut biodiesel with $4 \%$ paraffin and $91 \%$ diesel which is represented as AvBn_Pa. The mixture blends were investigated and compared with ultra-low-sulphur diesel (ULSD). The key parameters such as density, viscosity were kept lower and calorific value was maximized for better engine performance. A four-ball (TR-30H, DUCOM, Bohemia, NY, USA) test rig was used to assess the tribological characteristics of the tested fuels as illustrated in Figure 1. The test rig consists of four balls, three of which are stationary balls (Nos. 1, 2, and 3) sitting in a cup and submerged into the tested fuel with one rotating ball (No. 4) resting on the stationary balls and held by a spindle rotating at a constant speed at $1200 \mathrm{rpm}$. The specification of the tested ball materials and test conditions are presented in Table 1.

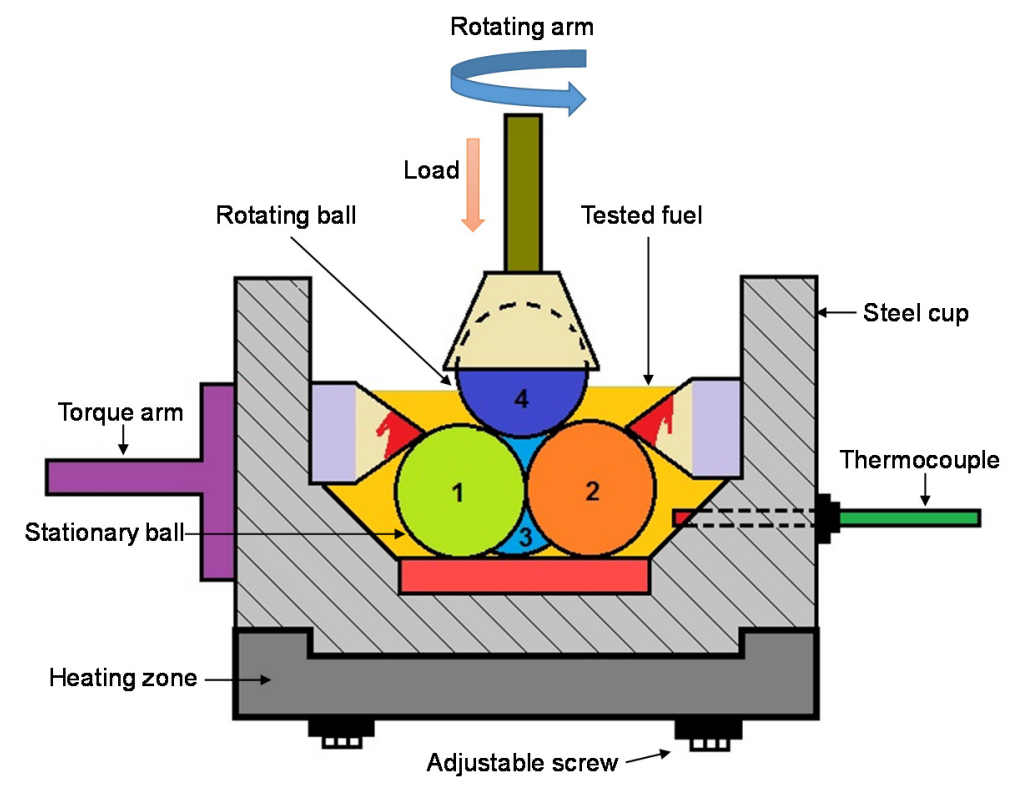

Figure 1. Schematic diagram of four-ball tribotester (TR-30H).

Table 1. Setup specification and experimental test condition.

\begin{tabular}{ccc}
\hline Items & Parameters & Description \\
\hline \multirow{3}{*}{ Specification } & Speed range & 300 to $3000 \mathrm{rpm}$ \\
& Temperature range & 25 to $1000^{\circ} \mathrm{C}$ \\
& Axial applied load & Maximum $1020 \mathrm{~kg}$ \\
& Scar range & 100 to $4000 \mathrm{micron}$ \\
& Drive motor power & $1.50 \mathrm{~kW}$ \\
\hline \multirow{3}{*}{ Test condition } & Applied load & $40 \mathrm{~kg}$ \\
& Rotation & $1200 \mathrm{rpm}$ \\
& Test duration & $3600 \mathrm{~s}$ \\
\hline \multirow{4}{*}{ Testing ball specification } & Diameter of the ball & $12.70 \mathrm{~mm}$ \\
& Materials & Carbon-chromium alloy steel \\
& Metal composition & $85.05 \% \mathrm{Fe}, 10.26 \% \mathrm{C}, 2.13 \% \mathrm{Zn}, 1.44 \% \mathrm{Cr}, 0.43 \% \mathrm{Si}$, \\
& $0.44 \% \mathrm{Mn}, 0.09 \% \mathrm{~S}, 0.13 \% \mathrm{P}$, and $0.06 \% \mathrm{Ni}$ \\
& Hardness of the metal & $62 \mathrm{HRc}$ \\
& Surface roughness & $0.10 \mu \mathrm{m}(\mathrm{C} . \mathrm{L} . \mathrm{A})$ \\
& Density & $7.87 \mathrm{gm} / \mathrm{cm}{ }^{3}$ \\
& Tensile strength & $325,000 \mathrm{psi}$ \\
& Yield strength & $295,000 \mathrm{psi}$ \\
\hline
\end{tabular}

The test was conducted using the ASTM D4172 standard method. Initially, the setup was prepared by washing the tested balls with $n$-heptane solution and wiping with soft tissue paper to dry. The oil 
cup was also cleaned and dried before being used for each test. The three balls were placed into the cup using tweezers, and the cup was filled with $10 \mathrm{~mL}$ of the fuel sample being tested which comes to about $3 \mathrm{~mm}$ over the stationary balls. During the test, the axial load of $40 \mathrm{~kg}$ was applied to the stationary balls by the loading arm according to the ASTM D4172 standard method. The friction torque (FT) was measured by the calibrated torque arm which is assembled with a friction recording device. This test was conducted at a nominal $75^{\circ} \mathrm{C}$ temperature which was controlled between $75^{\circ} \mathrm{C}$ to $80^{\circ} \mathrm{C}$ during the study using a thermostated bath. After completion of the test, the stationary balls were cleaned to laboratory standards. A high-resolution microscopy was performed on these balls using a high-resolution optical microscope in accordance with the ASTM D4172 standard. Finally, SEM/EDX analysis was conducted to evaluate the metal surface morphology of the tested balls. The FC and flash temperature parameter (FTP) were obtained using Equations (1) and (2), respectively. The friction coefficient can be expressed by Equation (1):

$$
\mu=\frac{\text { Torque }(\mathrm{kg}-\mathrm{mm}) \times \sqrt{6}}{3 \times \operatorname{Load}(\mathrm{kg}) \times \operatorname{Distance}(\mathrm{mm})}=\frac{T \sqrt{6}}{3 W r_{c}}
$$

where $T$ is friction torque in $\mathrm{kg}-\mathrm{mm}, W$ is applied load in $\mathrm{kg}, r_{c}$ is the distance in $\mathrm{mm}$ from the center of the lower ball contact surface to the axis of rotation. The value of $r_{c}=3.67 \mathrm{~mm}$ was measured for the test setup. In addition, flash temperature parameter (FTP) is a critical flash temperature at which the fuel fails its lubricating properties. It can be expressed by a solitary number as calculated using Equation (2):

$$
F T P=\frac{\text { Load }}{(W S D)^{1.4}}=\frac{W}{d^{1.4}}
$$

where $d$ is the WSD in mm which is obtained from the optical microscope (model C2000, IKA, Wilmington, NC, USA) with $\pm 0.01 \mathrm{~mm}$ resolution using the ASTM D4172 method. The focal point on the surface of the ball can be adjusted to obtain a better quality of image for analysis. The WSD was calculated from the mean value of the wear diameter obtained from the image. Then the metal surface morphology of the tested balls was obtained using a SEM with energy dispersive X-ray (EDX) analysis. The images from the SEM/EDX test were analysed to obtain wear on the metal surface indicating the corrosive behaviour of the tested fuels. The assessment of the parameters mentioned above could help to improve engine durability as well as the durability and total lifetime of the engine.

The uncertainty or error analysis was conducted to ensure the reliability of the test results. Mosarof et al. [5] reported that a high degree of uncertainty could occur due to instrument faults, test conditions, test environment, wrong test procedure and observation. More specifically, the uncertainty related to the tribological test as conducted is summarised in Table 2. The test was repeated three times to minimise the error of the result. Overall uncertainty related to wear and friction was found to be about $3.68 \%$ for this experiment which was well within the acceptable limits as verified by Mosarof et al. [5] and Habibullah et al. [7].

\begin{tabular}{|c|c|c|c|c|}
\hline \multirow{2}{*}{ Measurements } & \multicolumn{2}{|c|}{ FC } & \multirow{2}{*}{$W S D$} & \multirow{2}{*}{ FTP } \\
\hline & Run-in Period & Steady State & & \\
\hline Accuracy & \pm 0.50 & \pm 0.50 & $\pm 0.01 \mathrm{~mm}$ & \pm 0.50 \\
\hline Relative error & \pm 2.54 & \pm 1.27 & \pm 1.51 & \pm 2.76 \\
\hline
\end{tabular}

Table 2. Summary of uncertainty related to different parameters.

\section{Results and Discussions}

\subsection{Physiochemical Properties of the Fuel}

The important physiochemical properties of the tested fuel were measured using applicable ASTM and EN standards as shown in Table 3. The density was measured at the $15^{\circ} \mathrm{C}$ temperature and found 
$832 \mathrm{~kg} / \mathrm{m}^{3}$ for ULSD and $830.74 \mathrm{~kg} / \mathrm{m}^{3}$ for ManCr_Pa, $831.48 \mathrm{~kg} / \mathrm{m}^{3}$ for AvBn_Pa. The kinematic viscosity is another impacting parameter of the fuel which has a direct influence on lubrication behaviour of the mixture blends [22,23]. The result shows that the viscosity at $40{ }^{\circ} \mathrm{C}$ is $4.10 \mathrm{~mm}^{2} / \mathrm{s}$ for ULSD and AvBn_Pa but slightly less viscosity $\left(3.88 \mathrm{~mm}^{2} / \mathrm{s}\right)$ was found for ManCr_Pa. The literature reported that higher viscosity helps to create a stable lubrication film between two moving parts. It has a great influence to reduce friction coefficient which has briefly discussed in the following section. In addition, flashpoint in another property of the fuel which indicates the safety of the fuel. It is the temperature at which fuel starts to ignite. The result shows that biodiesel blends have higher flash point compare to ULSD. Furthermore, the study found the lower acid value $0.13 \mathrm{mgKOH} / \mathrm{g}$ for ManCr_Pa and $0.09 \mathrm{mgKOH} / \mathrm{g}$ for AvBn_Pa which indicates the fuel is very close to neutral and is not corrosive for the metal surface. Moreover, other important fuel properties such as cetane number, ester content, iodine value etc. are identified which have a direct and indirect influence on combustion characteristics of the fuel. The acid value and ester content of the fuel were measured for pure biodiesels mixture (i.e., ManCr and $\mathrm{AvBn}$ ) prior to add the paraffin as an additive. In addition, iodine value (IV) of the pure biodiesels mixture were calculated using Equation (3) [24]:

$$
I V=\sum\left(\frac{254 \times D_{b} \times A_{i}}{M W_{i}}\right)
$$

where, $A_{i}$ indicates the percentage of each fatty acid component, $M W_{i}$ is the molecular mass of each component by fatty acid methyl esters (FAMEs) analysis and $D_{b}$ is the number of double bonds present in the component.

Table 3. Physiochemical properties of the tested fuels.

\begin{tabular}{cccccc}
\hline Properties & Unit & ULSD & ManCr_Pa & AvBn_Pa & Used Standard \\
\hline Density (at $15{ }^{\circ} \mathrm{C}$ ) & $\mathrm{kg} / \mathrm{m}^{3}$ & 832.00 & 830.74 & 831.48 & ASTM D1298 \\
Viscosity $\left(\right.$ at $40{ }^{\circ} \mathrm{C}$ ) & $\mathrm{mm}^{2} / \mathrm{s}$ & 4.10 & 3.88 & 4.10 & ASTM D445 \\
Calorific value & $\mathrm{MJ} / \mathrm{kg}$ & 45.67 & 45.33 & 45.28 & ASTM D240 \\
Cetane number & - & 44.00 & 67.00 & $61: 00$ & ASTM D613 \\
Flash point & ${ }^{\circ} \mathrm{C}$ & 62.00 & 63.46 & 65.96 & ASTM D93 \\
Acid value * & $\mathrm{mgKOH} / \mathrm{g}$ & - & 0.13 & 0.09 & ASTM D664 \\
Ester content * & $\%$ & - & 95.75 & 99.64 & EN 14103 \\
Iodine value * & - & - & 47.86 & 87.00 & - \\
\hline
\end{tabular}

* Note: The fuel properties were measured for pure biodiesels mixture.

\subsection{Friction Behaviour Analysis}

The friction behaviour of the tested fuels was evaluated for $3600 \mathrm{~s}$ to the ASTM D4172 standard. The results reveal that, at the beginning of the test ( 0 to $10 \mathrm{~s}$ ), the FC exhibited a higher magnitude and unstable conditions which is denoted as the run-in period. The FC variation soon became stable and followed a steady state condition until the end of the test. This is due to several reasons as reported by Fazal at al. [14]. After the run-in period, the contact surface of the tested balls became smoother and prominent asperities were flattened or removed.

Figure 2 illustrates the variation of FC during the run-in period for all tested fuels. The ManCr_Pa mixture blend demonstrates the highest FC with a shorter run-in period compared to other fuels. This is due to the lower (about 5.25\%) dynamic viscosity of ManCr_Pa (3.23 mPa.s) compared to ULSD (3.41 mPa.s) which is one of the key parameters of lubrication properties as discussed above [2]. ULSD exhibits a higher FC compared to the AvBn_Pa blend with a longer run-in period. The results reveal that the AvBn_Pa mixture blend shows lower FC with shorter run-in duration compared to other fuels which implies the capability of biodiesel to prompt a change of unsteady state to steady state condition of FC for reducing friction. 


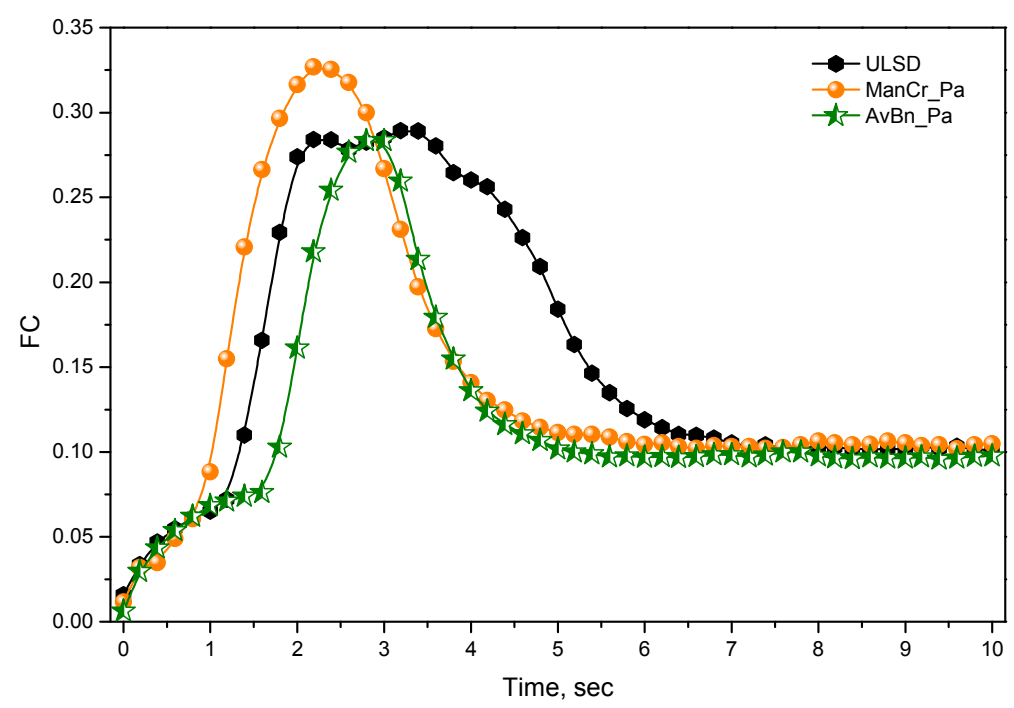

Figure 2. Variation of friction coefficient (FC) with time during the run-in period.

Figure 3 illustrates the variation of FC at steady state conditions for ULSD, ManCr_Pa and AvBn_Pa. The figure shows that the fluctuation of FC for ULSD is higher than for the other fuels which implies more friction occurred for fossil fuel compared to biodiesel. Similar results were also found by Mosarof et al. [2], Habibullah et al. [7] and Haseeb et al. [16]. The ManCr_Pa blend demonstrates minimal fluctuation of FC and a lower average FC compared to ULSD at steady state conditions. However, it shows higher FC during run-in conditions and transitioned to a steady state quickly as shown in Figure 2. This study found a significant reduction of FC for the AvBn_Pa blend in both the run-in period and the steady state period due to the long chain fatty acid content in this fuel. The FC reduction evidenced by the biodiesel blends implies that the ester molecules act as surfactants by creating a thin layer between the contact surfaces of the metals $[7,14]$. The results reveal that ManCr_Pa and AvBn_Pa blends reduced FC by about 6.5\% and 20.9\% compared to ULSD at steady state conditions, respectively. This study conducted an in-depth analysis of the lubricating behaviour of these fuels by showing a correlation between FT and FC which is presented in Figures 4-6.

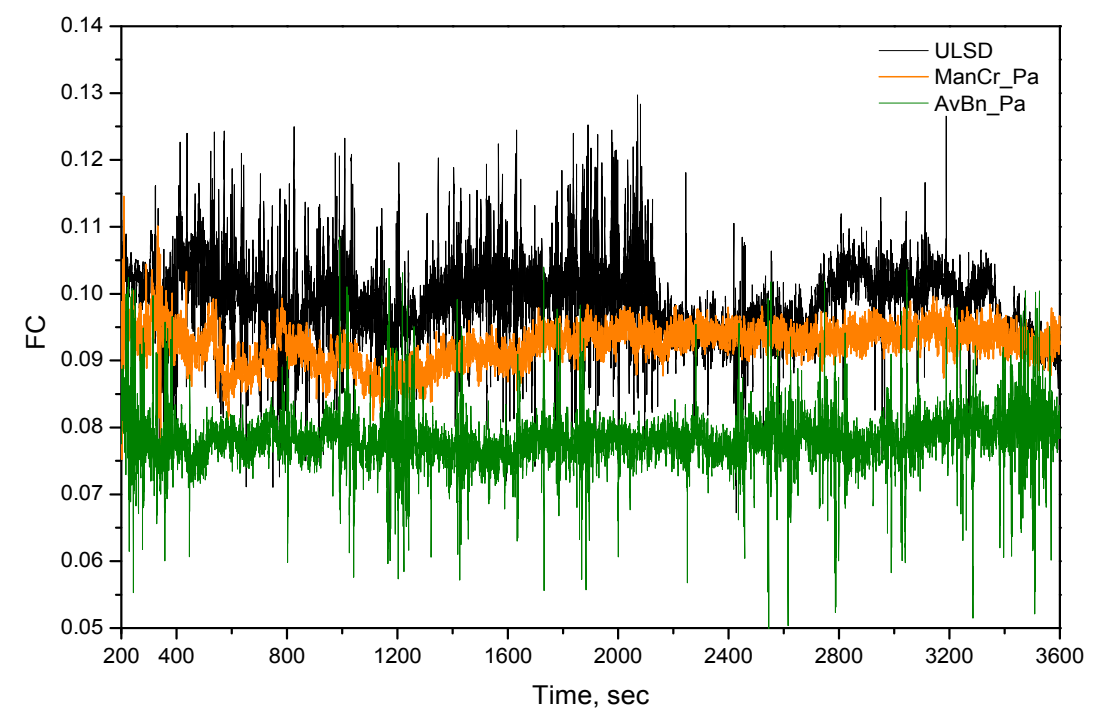

Figure 3. Variation of FC with time at steady state condition for ultra-low-sulphur diesel (ULSD), ManCr_Pa and AvBn_Pa. 
Figures 4-6 illustrate the correlation of FT and FC at steady state conditions for tested fuels. The figures show the variation of FC and FT with time at steady state conditions by black dot points and contour colour maps, respectively. More FT implies more energy loss due to friction which causes more wear on the metal surfaces as reported by [17]. Figure 4 demonstrates that the average FC value for ULSD varies between 0.09 and 0.11 within the range of 0.17 N.m to 0.19 N.m FT. However, this study found some higher values of FC at FT values above $0.22 \mathrm{~N}$.m which implies significant energy loss due to friction and higher wear on the metal surfaces [25]. Figure 5 demonstrates an average FC variation for ManCr_Pa between 0.089 and 0.97 within the range of 0.17 N.m to 0.79 N.m FT. It also shows higher values of FC at FT values above 0.18 N.m which is lower than for ULSD. Figure 6 demonstrates better tribological behaviour by AvBn_Pa with a reduced FC average ranging from 0.07 to 0.09 within the minimal FT range of 0.13 N.m to 0.15 N.m.

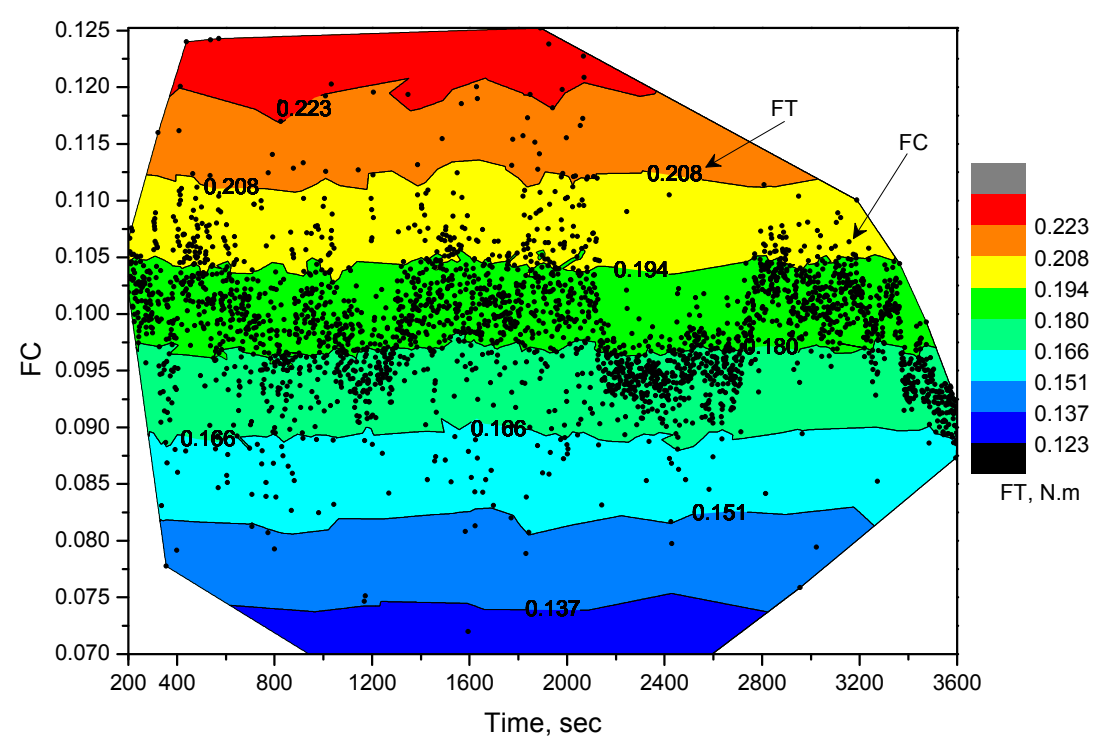

Figure 4. Correlation of friction torque (FT) and FC at steady state conditions for ULSD.

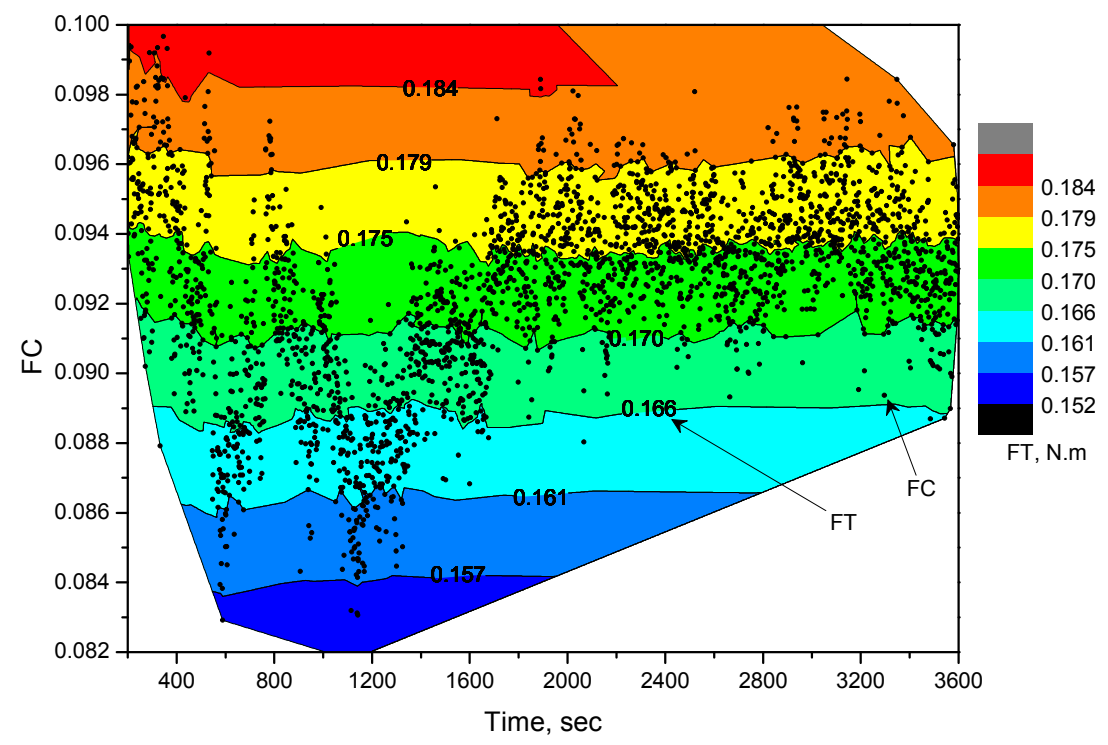

Figure 5. Correlation of FT and FC at steady state conditions for ManCr_Pa mixture blend. 


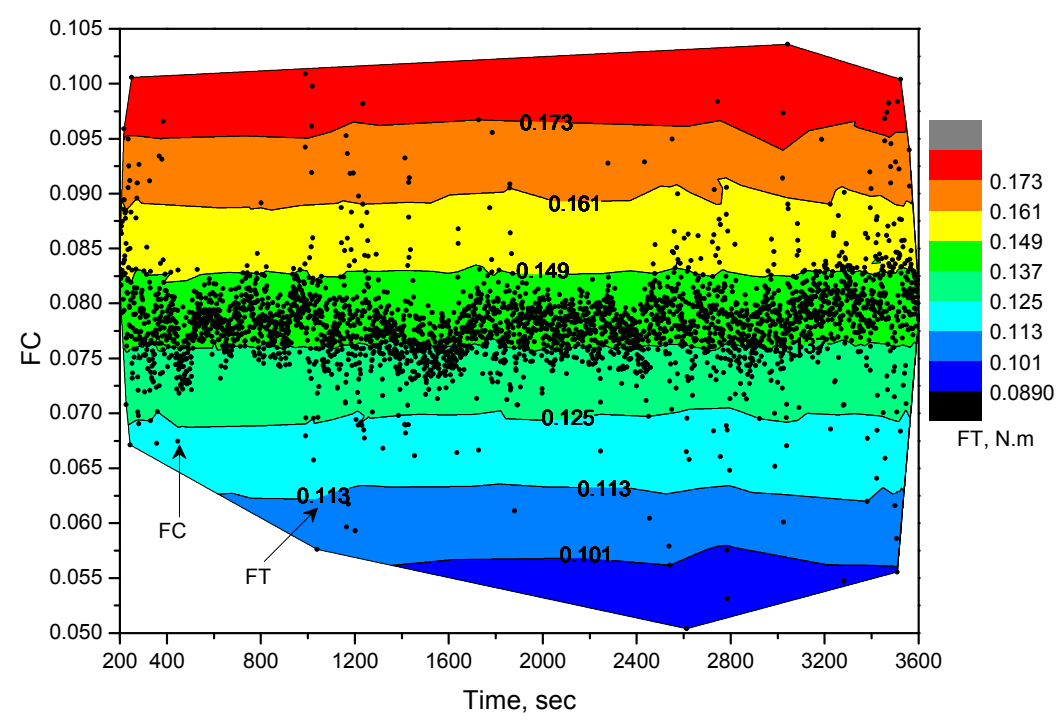

Figure 6. Correlation of FT and FC at steady state conditions for AvBn_Pa mixture blend.

This fuel shows an insignificant number of FC values at FT values above $0.173 \mathrm{~N}$.m. The results reveal that AvBn_Pa reduces FT by $23.70 \%$ compared to ULSD which implies lower frictional energy loss and minimum wear on the metal surfaces contributing to sustainable engine durability and improved engine reliability compared to fossil fuel. The wear analysis is briefly discussed in the following section.

\subsection{Wear Characteristics}

Figure 7 shows the mean WSD of the stationary balls used in the four-ball tribotester in this study. The balls were scanned by an optical microscope to assess the wear characteristics of ULSD, ManCr_Pa and AvBn_Pa blends at a constant speed, load and temperature condition. The major, minor and mean WSD and wear areas for each ball are summarised in Table 4. The results reveal that the highest WSD was found for ULSD and the lowest for AvBn_Pa blend under the same test conditions. As seen from Figure 7 and Table 3, the mean WSD was found to be $0.630 \mathrm{~mm}$ for ULSD which is $3.90 \%$ and $23.80 \%$ higher than for the ManCr_Pa and AvBn_Pa blends, respectively.

Table 4. Summary of wear characteristics of the tested fuels.

\begin{tabular}{|c|c|c|c|c|c|c|c|c|c|c|c|c|}
\hline \multirow[b]{2}{*}{$\begin{array}{c}\text { Tested } \\
\text { Balls }\end{array}$} & \multicolumn{4}{|c|}{ ULSD } & \multicolumn{4}{|c|}{ ManCr_Pa } & \multicolumn{4}{|c|}{ AvBn_Pa } \\
\hline & $\begin{array}{c}\text { Major } \\
W S D \\
\text { mm }\end{array}$ & $\begin{array}{c}\text { Minor } \\
W S D \\
\text { mm }\end{array}$ & $\begin{array}{c}\text { Mean } \\
W S D \\
\mathrm{~mm}\end{array}$ & $\begin{array}{l}\text { Area } \\
\mathrm{mm}^{2}\end{array}$ & $\begin{array}{c}\text { Major } \\
W S D \\
\text { mm }\end{array}$ & $\begin{array}{c}\text { Minor } \\
W S D \\
\mathrm{~mm}\end{array}$ & $\begin{array}{c}\text { Mean } \\
W S D \\
\mathrm{~mm}\end{array}$ & $\begin{array}{l}\text { Area } \\
\mathrm{mm}^{2}\end{array}$ & $\begin{array}{c}\text { Major } \\
W S D \\
\text { mm }\end{array}$ & $\begin{array}{c}\text { Minor } \\
W S D \\
\text { mm }\end{array}$ & $\begin{array}{c}\text { Mean } \\
W S D \\
\text { mm }\end{array}$ & $\begin{array}{l}\text { Area } \\
\mathrm{mm}^{2}\end{array}$ \\
\hline Ball 1 & 0.65 & 0.64 & 0.64 & 0.32 & 0.63 & 0.60 & 0.61 & 0.30 & 0.50 & 0.37 & 0.44 & 0.15 \\
\hline Ball 2 & 0.68 & 0.66 & 0.67 & 0.35 & 0.63 & 0.62 & 0.63 & 0.31 & 0.51 & 0.47 & 0.49 & 0.19 \\
\hline Ball 3 & 0.60 & 0.56 & 0.58 & 0.26 & 0.61 & 0.55 & 0.58 & 0.26 & 0.61 & 0.60 & 0.58 & 0.28 \\
\hline & \multicolumn{2}{|c|}{ Mean WSD } & \multicolumn{2}{|c|}{$0.63 \mathrm{~mm}$} & \multicolumn{2}{|c|}{ Mean WSD } & \multicolumn{2}{|c|}{$0.61 \mathrm{~mm}$} & \multicolumn{2}{|c|}{ Mean WSD } & \multicolumn{2}{|c|}{$0.51 \mathrm{~mm}$} \\
\hline
\end{tabular}

The WSD also depends on various operating conditions such as speed, load, temperature and oil compositions, etc. as reported by Maleque et al. [26]. For instance, Mosarof et al. [2] investigated the WSD of two biodiesels at different temperatures and loads with constant speed. They reported an increasing trend of WSD with both an increase in temperature and applied load. On the contrary, Fazal et al. [14] experimented by palm biodiesel at constant temperature and load but for varying speeds from $600 \mathrm{rpm}$ to $1500 \mathrm{rpm}$. They pointed out that WSD increased with increased speed but decreased for higher biodiesel blend proportions. There are some other reasons for improving lubricity which involve the FAMEs composition of the biodiesel [27]. Hu et al. [28] reported that the presence of mono and di-glycerides and free fatty acids in the biodiesel enhance the lubricity of the fuel. In addition, 
Fazal et al. [14] and Geller and Goodrum [29] have pointed out that the higher DU and longer CCL can play an important role to enhance lubrication properties of fuel.
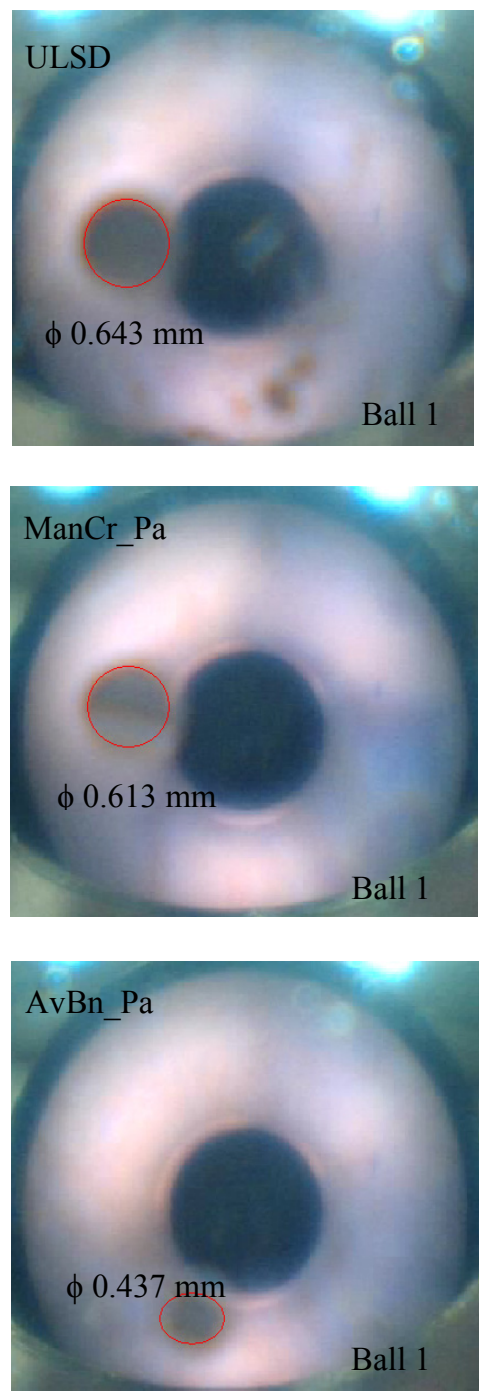
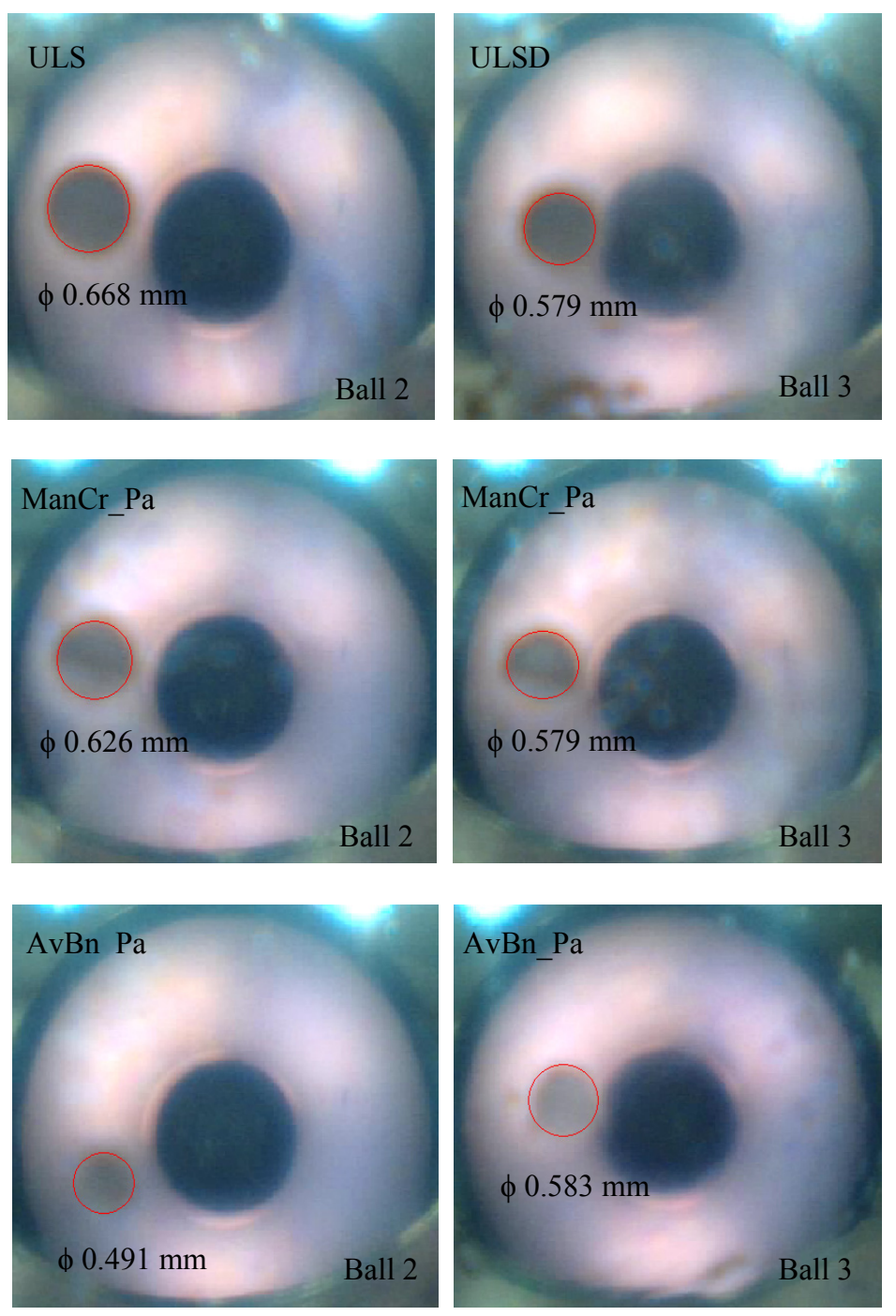

Figure 7. Optical microscope scanning image for wear scar diameter of the three stationary balls.

This study found a mean WSD of $0.61 \mathrm{~mm}$ for ManCr_Pa and $0.51 \mathrm{~mm}$ for AvBn_Pa biodiesel blends. The results reveal that the AvBn_Pa blend shows excellent wear reduction (about $19.20 \%$ ) characteristics compared to ULSD, whereas the ManCr_Pa blend demonstrates only $3.80 \%$ less WSD compared to ULSD. This could be due to the higher content of aliphatic acid $\left(\mathrm{C}_{n} \mathrm{H}_{2 n+1} \mathrm{COOH}\right)$ in the $\mathrm{AvBn} \_\mathrm{Pa}$ blend enhancing the lubricating properties to reduce friction and wear by creating a thin lubricating film between the metal surfaces. This has already been agreed by many researchers such as Habibullah el al. [7], Fazal et al. [14] and Syahrullail et al. [30]. In addition, the longer CCL of biodiesel contributes to thickening of the lubricating film which creates a more protected surface area on the metal contact surface as reported by Havet et al. [31]. In this study, Avocado and Bush nut biodiesels have a high saponification number of about 200.9 and 196.23, respectively which implies longer CCL compared to other biodiesels. The mean wear scan area for AvBn_Pa is $0.21 \mathrm{~mm}^{2}$ whereas it is $0.31 \mathrm{~mm}^{2}$ for ULSD and $0.28 \mathrm{~mm}^{2}$ for ManCr_Pa which implies AvBn_Pa has provided more protection to the contact surfaces (about $32.20 \%$ more compared to ULSD). 


\subsection{Flash Temperature Parameter Analysis}

The FTP is the minimum temperature below which the fuels can sustain their lubricating properties which implies the capability of the fuel to create a lubricating film on the metal contact surface. The higher magnitude of FTP denotes a lower potential for the scuffing phenomenon which occurs at high temperature at TDC (top dead centre) due to inadequate lubrication. The engine performance significantly decreases due to this effect as reported by Shuster et al. [32] and Azad et al. [33]. It also implies the stability of the lubrication properties and the lower potential for film breakdown at different operating conditions as reported by Habibullah et al. [34]. The FTP values of the tested fuels were calculated using Equation (2). Figure 8 illustrates the correlation of FTP and WSD of the tested fuels. The figure shows FTPs of $76.38^{\circ} \mathrm{C}$ for ULSD, $80.61^{\circ} \mathrm{C}$ for ManCr_Pa and $102.96^{\circ} \mathrm{C}$ for AvBn_Pa. The results reveal that FTP increases with the decrease of WSD of the fuel. The FTP value of $102.96{ }^{\circ} \mathrm{C}$ for AvBn_Pa implies that the fuel is capable of sustaining its lubricating properties below this temperature. This higher magnitude of FTP indicates about $35 \%$ more lubricating film reliability by the AvBn_Pa blend compared to ULSD which could enhance the sustainabile of the engine durability. Thus AvBn_Pa can withstand higher temperatures before scuffing takes place and the lubricating film breaks down in the contact.

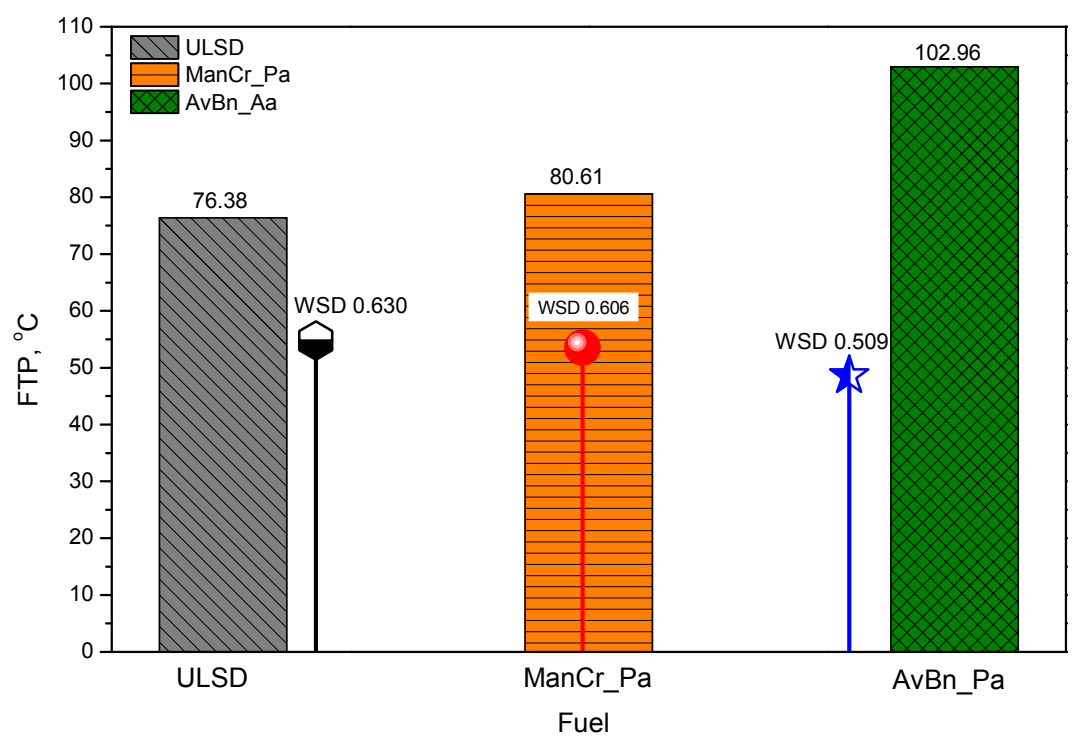

Figure 8. Correlation of FTP and WSD of the tested fuels.

\section{Wear Debris and Surface Morphology by SEM/EDX}

\subsection{Evaluation of Filtered Wear Debris by SEM/EDX}

Wear debris analysis is one of the key techniques to evaluate wear particle counts and measure their sizes for the tested fuels. This study was conducted using the wear debris analysis by SEM/EDX on the filtered metal debris samples which were collected by filtering the oil from the four-ball tribotester. In the analysis of different spots on the filter paper, mainly iron (Fe), chromium $(\mathrm{Cr})$, silicon $(\mathrm{Si})$, carbon $(\mathrm{C})$ and oxygen $(\mathrm{O})$ were found and recorded in average percentages of weight and atomic concentration. The results of the wear debris analysis in this experiment are presented in Table 5 and Figure 9. The results reveal that the maximum particle concentration was found for ULSD and the minimum was for the AvBn_Pa. This indicates that highest friction and wear occurred for ULSD and these were the lowest for AvBn_Pa. The average particle size of the wear debris was measured for each fuel. The particle sizes found were in the ranges of about 1.75 to $13.70 \mu \mathrm{m}$ for ULSD, 1.71 to $15.50 \mu \mathrm{m}$ for ManCr_Pa and 3.57 to $13.00 \mu \mathrm{m}$ for AvBn_Pa (Figure 10). The larger particle sizes of the 
wear debris can break down the lubricant film and cause adhesive wear on the metal surfaces which has also been reported by Habibullah et al. [7].

Figure 9 illustrates the particle concentrations in both weight and atomic percentage from the SEM/EDX analysis. The figure shows that higher Fe and lower $\mathrm{C}$ and $\mathrm{O}$ concentrations were found for ULSD compared to the other fuels which implies ULSD caused more metal surface wear. On the other hand, $\mathrm{C}$ and $\mathrm{O}$ concentrations were found to be higher for the biodiesels compared to ULSD. In addition, about $0.59 \%$ wt. $\mathrm{Cr}$ and $0.27 \%$ wt. Si were identified for ULSD and ManCr_Pa, respectively.

Similar results were also reported by Mosarof et al. [2] and Habibullah et al. [7]. The results reveal that the higher O concentration in AvBn_Pa blend produced more oxides on the metal surfaces which enhanced the lubricity of the fuel as agreed by Lu et al. [35].

Table 5. Wear debris analysis of the filtering particles by SEM/EDX.

\begin{tabular}{ccccccc}
\hline \multirow{2}{*}{ Element } & \multicolumn{2}{c}{ ULSD } & \multicolumn{2}{c}{ ManCr_Pa } & \multicolumn{2}{c}{ AvBn_Pa } \\
\cline { 2 - 7 } & Weight $\%$ & Atomic $\%$ & Weight $\%$ & Atomic $\%$ & Weight \% & Atomic \% \\
\hline Fe & 22.90 & 6.74 & 16.57 & 4.44 & 8.97 & 2.27 \\
$\mathrm{C}$ & 64.87 & 81.98 & 66.11 & 79.85 & 65.24 & 75.26 \\
$\mathrm{O}$ & 12.03 & 11.21 & 17.23 & 15.65 & 25.84 & 22.47 \\
$\mathrm{Cr}$ & 0.59 & 0.21 & - & - & - & - \\
$\mathrm{Si}$ & - & - & 0.27 & 0.14 & - & - \\
\hline Particle size, $\mu \mathrm{m}$ & \multicolumn{2}{c}{$1.75-13.70$} & \multicolumn{2}{c}{$1.41-15.50$} & \multicolumn{2}{c}{$3.57-13.00$} \\
\hline
\end{tabular}

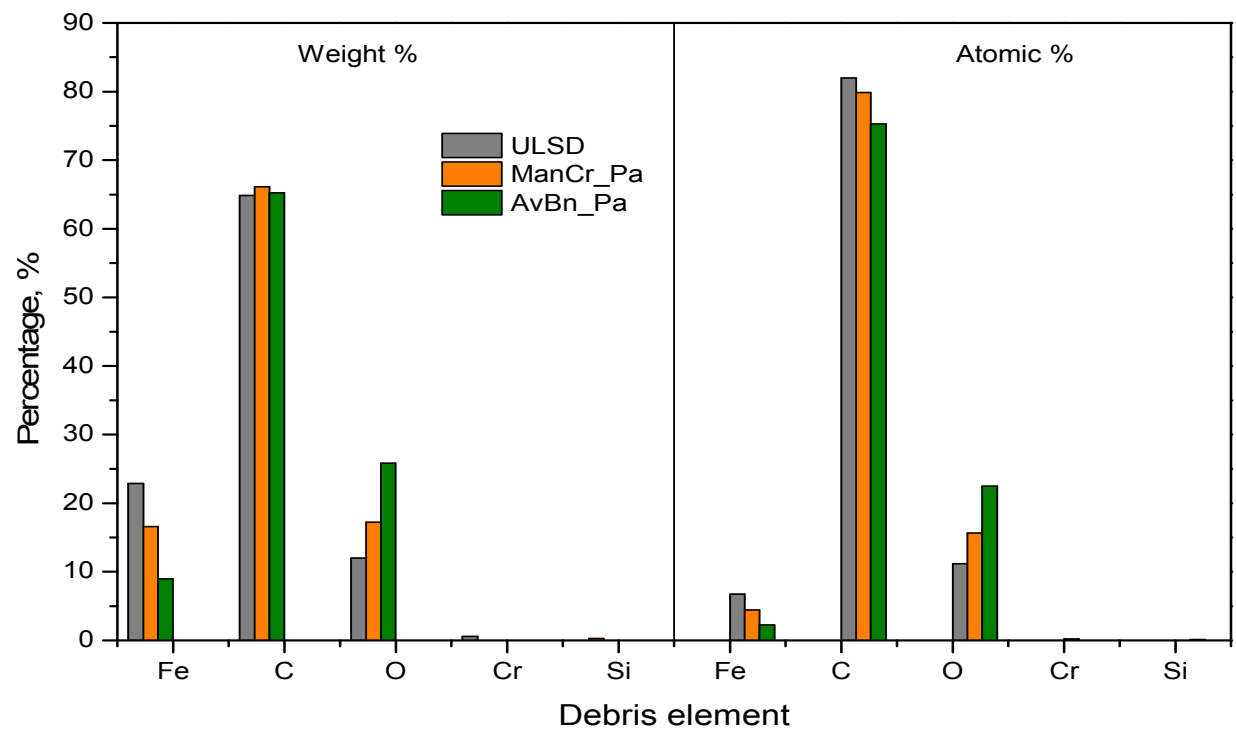

Figure 9. Filtered wear debris analysis by SEM/EDX. 

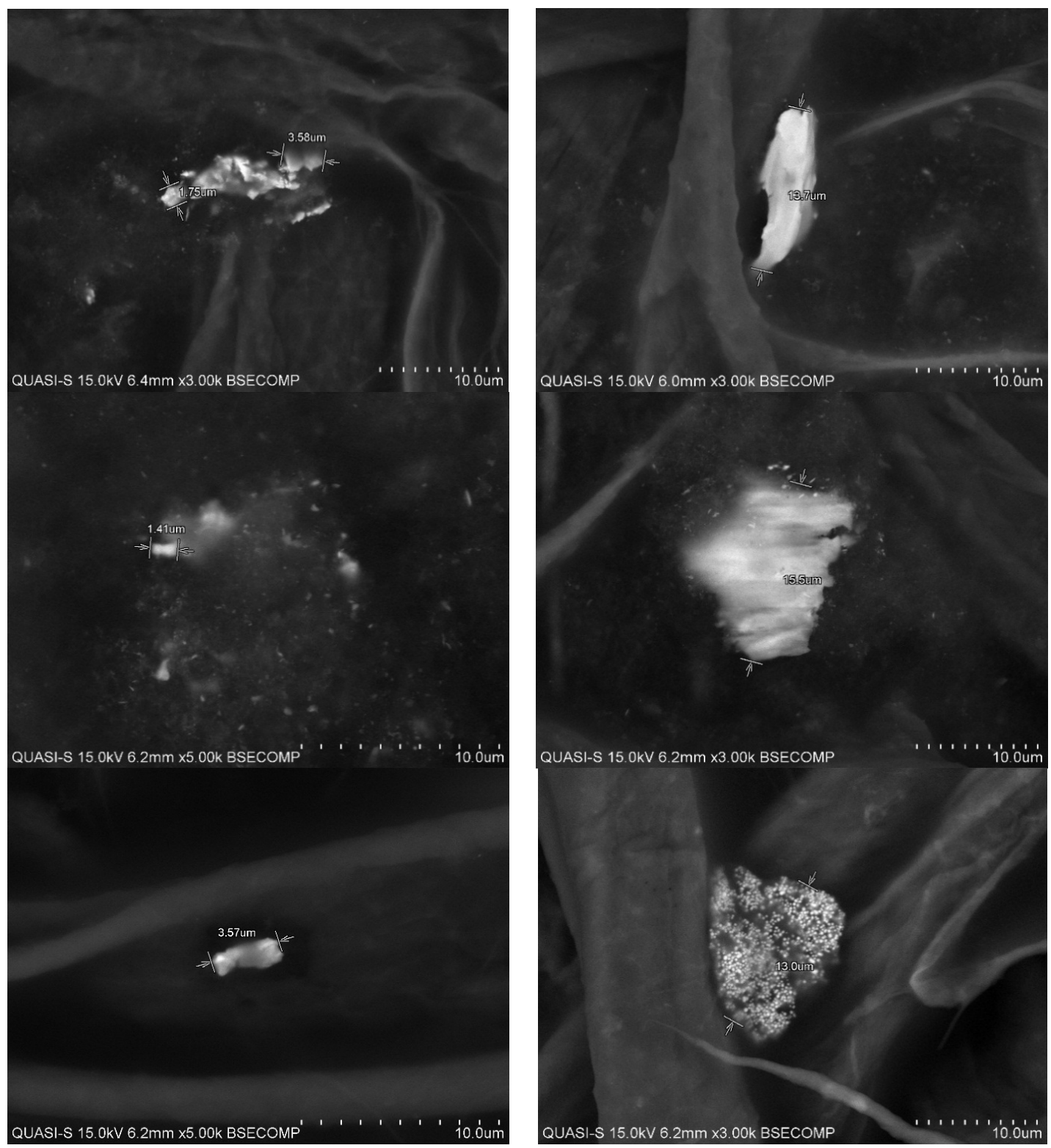

Figure 10. Minimum and maximum particle sizes of filtered wear debris by SEM/EDX microscopy.

\subsection{Wear Surface Analysis by SEM/EDX}

The wear surface morphology of the stationary balls was evaluated using SEM and the images of scar-worn surfaces are presented in Figure 11. The results reveal that significant surface deformation and cracks were identified for ULSD and the ManCr_Pa blend. Lots of micro cracks and corrosive delamination were also identified on the metal surfaces for ULSD and ManCr_Pa. The surface morphology reveals that the metal layers were removed from the worn surface by the rotating balls in their sliding direction as shown in Figure 11. Adhesive wear was identified on the sliding surfaces due to the greater wear debris particle size, as discussed above. The surface damage was identified to be more than $20 \mu \mathrm{m}$ which implied this effect [17].

The AvBn_Pa blend exhibits smaller worn surfaces $(300 \mu \mathrm{m})$ whereas ULSD and ManCr_Pa had $500 \mu \mathrm{m}$ worn surfaces as shown in Figure 11. In addition, bigger fractures and fewer cracks were identified for AvBn_Pa but lubricating film-protected smooth surface was observed in major portions of the metal surface. This result is expected due to the longer carbon chain length (CCL) and degree of unsaturation (DU) and activated ester creates a monolayer film on the metal surface. On the contrary, 
higher oxygen content produced more metal oxides which enhance the lubrication film on the sliding surface. Hence, reduce friction and wear between the contact surfaces for AvBn_Pa blend.
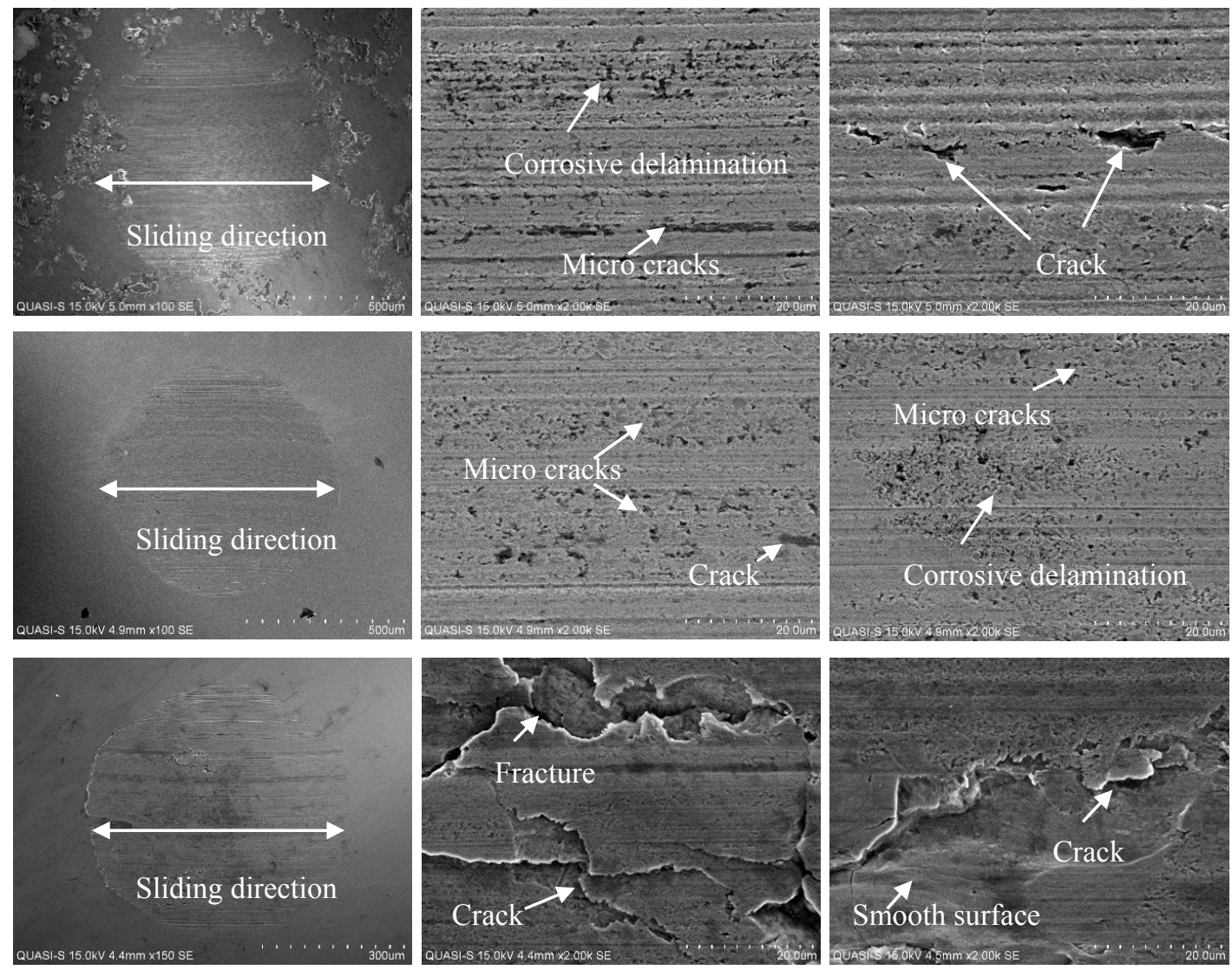

Figure 11. SEM worn surface images for ULSD, ManCr_Pa and AvBn_Pa fuels.

The EDX analysis of the metal surfaces was conducted for all tested balls and identified Fe, C, $\mathrm{O}, \mathrm{Si}$, and $\mathrm{Cr}$ by both weight and atomic percentage. The results reveal a lower $\mathrm{C}$ content on the ball surfaces of about $4.44 \mathrm{wt}$. \% for ULSD with $4.69 \mathrm{wt}$ \% $\mathrm{C}$ for ManCr_Pa, and a high C of about 7.56 wt. \% for AvBn_Pa. This higher percentage of $\mathrm{C}$ reinforces the conclusion of greater lubricating film stability on the metal surfaces which help to reduce friction and wear on the metal contact surfaces for the AvBn_Pa blend. In all aspects, the AvBn_Pa mixture blend demonstrated better tribological behaviour compared to the other fuels.

\section{Conclusions}

The tribological study was conducted on the three better-performing fuels derived from the engine tests on a four-ball tribotester using the ASTM D4172 test standard. The physiochemical properties of the fuel blends were tested and compared with each other. The study identified that higher density and viscosity of AvBn_Pa blend has great influence on lubrication behaviour on the metal surface. It can be concluded from this study that the AvBn_Pa biodiesel mixture blend shows less friction in both the run-in period and steady state conditions as an indicator of rich lubrication capability. This blend demonstrated more protected contact surface area and less mean WSD compared to other fuels. The higher FTP value of these blends exhibits a more reliable lubricating film that could sustain higher load and speeds without reaching the scuffing stage. The AvBn_Pa biodiesel blend exhibits overall better lubrication performance on the four-ball tester which was further validated by the surface morphology analysis via SEM/EDX high-resolution microscopy. The analysis shows less micro crack and smooth metal surface compared to other fuels. Thus, the AvBn_Pa blend is the best 
blend in all aspects of tribological characteristics for energy saving, engine reliability and sustainable engine durability.

Acknowledgments: The authors would also like to acknowledge Tim McSweeney, Adjunct Research Fellow, Centre for Railway Engineering at Central Queensland University for his contribution in English proof reading of this article.

Author Contributions: Abul Kalam Azad produced biodiesel from the new sources, tested fuel properties and prepared mixture, collected all experimental data, analysed the numerical results, drafted and revised the manuscript; Mohammad Golam Rasul contributed to design the experiment and provided feedback of the paper; Subhash Chandra Sharma also helped to design experimental procedure and provided feedback. Mohammad Masud Kamal Khan revise the paper according to the reviewer comments.

Conflicts of Interest: The authors declare no conflict of interest.

\section{References}

1. Nagar, P.; Miers, S. Friction between Piston and Cylinder of an IC Engine: A Review; SAE Technical Paper; SAE International: Warrendale, PA, USA, 2011.

2. Mosarof, M.H.; Kalam, M.A.; Masjuki, H.H.; Alabdulkarem, A.; Habibullah, M.; Arslan, A.; Monirul, I.M. Assessment of friction and wear characteristics of Calophyllum inophyllum and palm biodiesel. Ind. Crops Prod. 2016, 83, 470-483. [CrossRef]

3. Azad, A.K.; Rasul, M.G.; Khan, M.M.K.; Sharma, S.C.; Hazrat, M.A. Prospect of Biofuels as an Alternative Transport Fuel in Australia. Renew. Sustain. Energy Rev. 2015, 43, 331-351. [CrossRef]

4. Tung, S.C.; McMillan, M.L. Automotive tribology overview of current advances and challenges for the future. Tribol. Int. 2004, 37, 517-536. [CrossRef]

5. Mosarof, M.; Kalam, M.; Masjuki, H.; Arslan, A.; Monirul, I.; Ruhul, A.; Shahir, S.; Khuong, L. Analysis of thermal stability and lubrication characteristics of Millettia pinnata oil. RSC Adv. 2016, 6, 81414-81425. [CrossRef]

6. Holmberg, K.; Andersson, P.; Erdemir, A. Global energy consumption due to friction in passenger cars. Tribol. Int. 2012, 47, 221-234. [CrossRef]

7. Habibullah, M.; Masjuki, H.H.; Kalam, M.A.; Zulkifli, N.W.M.; Masum, B.M.; Arslan, A.; Gulzar, M. Friction and wear characteristics of Calophyllum inophyllum biodiesel. Ind. Crops Prod. 2015, 76, 188-197. [CrossRef]

8. Uddin, S.M.A.; Azad, A.K.; Alam, M.M.; Ahamed, J.U. Performance of a diesel engine run with mustard-kerosene blends. Procedia Eng. 2015, 105, 698-704. [CrossRef]

9. Azad, A.K.; Rasul, M.G.; Giannangelo, B. Comparative study of diesel engine performance and emission with soybean and waste oil biodiesel fuels. Int. J. Automot. Mech. Eng. 2015, 12, 2866-2881. [CrossRef]

10. Azad, A.K.; Rasul, M.G.; Khan, M.M.K.; Sharma, S.C.; Mofigur, M.; Bhuiya, M.M.K. Prospects, feedstocks, and challenges of biodiesel production from beauty leaf oil and castor oil: A non-edible oil sources in Australia. Renew. Sustain. Energy Rev. 2016, 61, 302-318. [CrossRef]

11. Azad, A.K.; Rasul, M.G.; Khan, M.M.K.; Sharma, S.C.; Islam, R. Prospect of Moringa seed oil as a sustainable biodiesel fuel in Australia: A review. Procedia Eng. 2015, 105, 601-606. [CrossRef]

12. Bhuiya, M.M.K.; Rasul, M.G.; Khan, M.M.K.; Ashwath, N.; Azad, A.K.; Mofijur, M. Optimisation of oil extraction process from Australian native beauty leaf seed (Calophyllum Inophyllum). Energy Procedia 2015, 75, 56-61. [CrossRef]

13. Mofijur, M.; Rasul, M.G.; Hyde, J.; Azad, A.K.; Mamat, R.; Bhuiya, M. Role of biofuel and their binary (diesel-biodiesel) and ternary (ethanol-biodiesel-diesel) blends on internal combustion engines emission reduction. Renew. Sustain. Energy Rev. 2016, 53, 265-278. [CrossRef]

14. Azad, A.K.; Uddin, S.M.A.; Alam, M.M. A comprehensive study of di diesel engine performance with vegetable oil: an alternative bio-fuel source of energy. Int. J. Automot. Mech. Eng. 2012, 5, 576-586. [CrossRef]

15. Fazal, M.A.; Haseeb, A.S.M.A.; Masjuki, H.H. Investigation of friction and wear characteristics of palm biodiesel. Energy Convers. Manag. 2013, 67, 251-256. [CrossRef]

16. Haseeb, A.S.M.A.; Sia, S.Y.; Fazal, M.A.; Masjuki, H.H. Effect of temperature on tribological properties of palm biodiesel. Energy 2010, 35, 1460-1464. [CrossRef] 
17. Mosarof, M.H.; Kalam, M.A.; Masjuki, H.H.; Alabdulkarem, A.; Ashraful, A.M.; Arslan, A.; Rashedul, H.K.; Monirul, I.M. Optimization of performance, emission, friction and wear characteristics of palm and Calophyllum inophyllum biodiesel blends. Energy Convers. Manag. 2016, 118, 119-134. [CrossRef]

18. Azad, A.K.; Rasul, M.G.; Khan, M.M.K.; Omri, A.; Bhuiya, M.M.K.; Hazrat, M.A. Modelling of renewable energy economy in Australia. Energy Procedia 2014, 61, 1902-1906. [CrossRef]

19. Azad, A.K.; Rasul, M.G.; Khan, M.M.K.; Sharma, S.C.; Bhuiya, M.M.K.; Mofijur, M. A Review on Socio-economic Aspects of Sustainable Biofuels. Int. J. Glob. Warm. 2016, 10, 32-54. [CrossRef]

20. Azad, A.K.; Uddin, S.M.A. Performance study of a diesel engine by first generation bio-fuel blends with fossil fuel: an experimental study. J. Renew. Sustain. Energy 2013, 5, 1-12. [CrossRef]

21. Fazal, M.A.; Haseeb, A.S.M.A.; Masjuki, H.H. Comparative corrosive characteristics of petroleum diesel and palm biodiesel for automotive materials. Fuel Process. Technol. 2010, 91, 1308-1315. [CrossRef]

22. Azad, A.K.; Rasul, M.G.; Khan, M.M.K.; Sharma, S.C. Macadamia biodiesel as a sustainable and alternative transport fuel in Australia. Energy Procedia 2017, 110, 543-548. [CrossRef]

23. Azad, A.K.; Rasul, M.G.; Khan, M.M.K.; Sharma, S.C.; Bhuiya, M.M.K. Recent development of biodiesel combustion strategies and modelling for compression ignition engines. Renew. Sustain. Energy Rev. 2016, 56, 1068-1086. [CrossRef]

24. Azad, A.K. Biodiesel from Mandarin Seed Oil: A Surprising Source of Alternative Fuel. Energies 2017, 10, 1689. [CrossRef]

25. Zulkifli, N.W.M.; Kalam, M.A.; Masjuki, H.H.; Shahabuddin, M.; Yunus, R. Wear prevention characteristics of a palm oil-based TMP (trimethylolpropane) ester as an engine lubricant. Energy 2013, 54, 167-173. [CrossRef]

26. Maleque, M.; Masjuki, H.; Haseeb, A. Effect of mechanical factors on tribological properties of palm oil methyl ester blended lubricant. Wear 2000, 239, 117-125. [CrossRef]

27. Pehan, S.; Jerman, M.S.; Kegl, M.; Kegl, B. Biodiesel influence on tribology characteristics of a diesel engine. Fuel 2009, 88, 970-979. [CrossRef]

28. Hu, J.; Du, Z.; Li, C.; Min, E. Study on the lubrication properties of biodiesel as fuel lubricity enhancers. Fuel 2005, 84, 1601-1606. [CrossRef]

29. Geller, D.P.; Goodrum, J.W. Effects of specific fatty acid methyl esters on diesel fuel lubricity. Fuel 2004, 83, 2351-2356. [CrossRef]

30. Syahrullail, S.; Wira, J.Y.; Wan Nik, W.; Fawwaz, W. Friction characteristics of RBD palm olein using four-ball tribotester. Appl. Mech. Mater. 2013, 315, 936-940. [CrossRef]

31. Havet, L.; Blouet, J.; Valloire, F.R.; Brasseur, E.; Slomka, D. Tribological characteristics of some environmentally friendly lubricants. Wear 2001, 248, 140-146. [CrossRef]

32. Shuster, M.; Combs, D.; Karrip, K.; Burke, D. Piston Ring Cylinder Liner Scuffing Phenomenon Studies Using Acoustic Emission Technique; SAE Technical Paper; SAE International: Warrendale, PA, USA, 2000.

33. Azad, A.K.; Rasul, M.G.; Bhuiya, M.M.K.; Islam, R. Effect of first and second generation biodiesel blends on engine performance and emission. AIP Conf. Proced. 2016, 1754, 050031.

34. Habibullah, M.; Masjuki, H.H.; Kalam, M.A.; Gulzar, M.; Arslan, A.; Zahid, R. Tribological Characteristics of Calophyllum inophyllum-Based TMP (Trimethylolpropane) Ester as Energy-Saving and Biodegradable Lubricant. Tribol. Trans. 2015, 58, 1002-1011. [CrossRef]

35. Lu, X.; Cotter, J.; Eadie, D. Laboratory study of the tribological properties of friction modifier thin films for friction control at the wheel/rail interface. Wear 2005, 259, 1262-1269. [CrossRef]

(C) 2017 by the authors. Licensee MDPI, Basel, Switzerland. This article is an open access article distributed under the terms and conditions of the Creative Commons Attribution (CC BY) license (http:/ / creativecommons.org/licenses/by/4.0/). 